\title{
Estimation of the Bulk and Shear Moduli of Soil Surrounding a Plastic Water Pipe using Measurements of the Predominantly Fluid Wave in the Pipe
}

\author{
O. Scussel $^{a^{*}}$, M.J. Brennan ${ }^{a}$, J.M. Muggleton ${ }^{b}$, F.C.L Almeida ${ }^{c}$, A.T. Paschoalini ${ }^{a}$. \\ a Department of Mechanical Engineering, UNESP, Ilha Solteira, São Paulo, 15385-000, Brazil \\ b Institute of Sound and Vibration Research, University of Southampton, Highfield, SO17 1BJ, \\ Southampton, United Kingdom. \\ ${ }^{\mathrm{c}}$ Faculty of Science and Engineering, UNESP, Tupã, São Paulo, 17602-496, Brazil \\ * Corresponding author email: oscar.scussel@gmail.com
}

No of pages: 21

No of figures: 8

No of tables: 3

No of references: 32

Manuscript submitted to the Journal of Applied Geophysics. 


\section{Abstract}

Leak noise correlators are commonly used to detect and locate leaks in buried water pipes. They use the cross-correlation function between leak noise signals measured using hydrophones or accelerometers placed on the pipe either side of the leak. The efficacy of a correlator is dependent upon knowledge of the speed at which the leak noise propagates along the pipe as well as how much it attenuates with distance. The leak noise is carried in a predominantly fluid-borne wave in the pipe, which is heavily influenced by the pipe and soil properties. Although the pipe properties can be determined relatively easily, estimation of the soil properties surrounding the pipe is more problematic. It is desirable to have an accurate estimate of the soil properties, so that current models can be developed and used to improve understanding of leak noise propagation and hence leak detection capabilities. In this paper a novel approach to determining the bulk and shear moduli of the soil from measurements of the predominantly fluid-borne wave in a buried plastic pipe, is described. The measured data are compared with corresponding data predicted from a model, and the soil properties are determined using an optimization algorithm. The method is applied to two different sites, one in the UK, where the soil properties surrounding the pipe are representative of sandy soil, and one in Brazil, where the surrounding soil has properties that are representative of clay soil. It is found that the bulk and shear modulus can be estimated in the pipe buried in sandy soil, but in the clay soil it is only possible to estimate the shear modulus.

Keywords: water leak detection; fluid-pipe-soil interaction; soil properties; optimization 


\section{Introduction}

In recent years, the increasing scarcity of fresh water due to wastage and leakage has been of great concern [1,2,3]. Detection and location of leaks in buried pipelines are an important part of tackling this problem [4]. Approximately $40 \%$ to $50 \%$ of water is lost globally in developing countries mostly due to leaks in buried pipelines, which in some extreme cases may exceed $70 \%$ of the potable water supply, resulting in social, economic and environmental effects [58].

If a leak occurs in a plastic pipe, the noise generated propagates along the pipe in the form of a predominantly fluid-borne wave and this theory has been extensively investigated throughout the past 70 years [9-15]. Lin an Morgan [9] presented in 1956 an investigation into the propagation of axisymmetric waves through fluid contained in clyndrical elastic shells and the phase velocity behaviour for different pipe vibrating modes based on dispersions curves. Five years later, Greenspon [10] proposed an interesting study covering the free and force vibrations of thick and thin cylindrical shells surrounded by water. It was the one of the percursors studying the case where the pipe is surrounded by an infinite elastic medium with numerical approximations to treat the effects of static pressure, internal fluid and structural damping. Comparisons between natural frequencies in vacuum and in water were also carried out. Two decades later, Fuller and Fahy [11] examined the dispersion and energy distributions of free waves in fluid-filled cylindrical shells. The authors provided a new equation to determine the distribution of vibrational energy between the pipe-wall and the contained fluid as well as its variation with frequency and material properties. Sinha et al. [12] carried out an inovative analyses of axisymmetric waves propagating along the fluid-filled pipes within the framework o linear elasticity and perfect-slip conditions at the solid-fluid interface. A study of modal propagation of harmonic waves in a steel cylindrical shell immersed in water in which the 
eigensolutions form the basis for the analysis of several more complex propagation studies that involves pulse propagation an perturbation analysis. A couple of years later, Pinnington and Briscoe [13] investigated the sensitivity of the transducer to the two axymetric waves, predominantly fluid-borne wave $s=1$ and predominantly compressional wave in the pipe $s=2$. The authors discussed the relative sizes of these two wave types for different boundary conditions in order to establish the conditions where only one wave type needs to be taken into account. Pinnington [14] derived the equation of motion for axsymetric waves in a fluid-filled, internally pressurized an axially tensioned pipe. The dispersion curves for these waves were plotted for various loading conditions where the author verified that fluid loading caused large changes to the $s=1$ predominantly fluid wave speed and small changes to the axial wave in the shell $s=2$. More recently, Khulief et al. [15] presented an experimental investigation addresing the feasibility and benefits of in-pipe acoustic measurements aiming leak detection.

The physical behaviour of the predominantly fluid-borne wave $s=1$, in which there is strong coupling between the water, the pipe-wall and the surrounding soil, has been studied extensively in underground sructures [16-17]. The soil-pipeline interaction under a frictional interface subjected to seismic excitation was firstly investigated by Akiyoshi and Fuchida [17]. Two decades later, Muggleton et al. [18] developed a theoretical model, wich is an extention of Pinnington and Briscoe [13], to predict both wave speed and attenuation of a buried pipe filled with fluid. The soil was treated as a fluid supporting two different waves, each of wich exerted normal dynamic preessure on the pipe wall. Although the shear coupling of the pipe to the surrounding soil was not properly accounted for, the theoretical and experimental results showed good agreement at low frequencies. At higher frequencies, however, the results matched the in vacuum case better than the buried pipe cased predictions due to possible uncertainties in the soil properties or even the effects of the ground surface. Some subsequent 
works have also investigated the wave propagation and vibration characteristics of buried pipes under slip pipeline-soil interface [19-21].

It is known that the soil properties have a profound effect on both the speed of the leak noise propagation along the pipe (wave speed), and the attenuation of this wave [22-26]. The works discussed hitherto did not model the soil effectively, as it was treated as a fluid supporting elastic waves in the soil. These properties were considered in subsequent work by Muggleton and Yan [23]. However, they described an incomplete model in which the soil connected to the pipe in the radial direction, but was not connected in the axial direction. In effect, there was a lubricated contact between the pipe and the surrounding soil. The authors then derived analytical expressions for the predominantly fluid-borne $s=1$ wave. Later, Gao et al. [24] proposed a more complete model in which the pipe connected to the soil both radially and axially. They carried out their investigation by an analytical method in which the effect of the soil loading on the pipe response is characterized by the soil loading matrix. An extended version of this model was later discussed by Gao et al. [25] who investigated the loading effects of the surrounding elastic medium.

Leak noise correlators are often used to detect and locate leaks by sensing acoustic pressure in the pipe or pipe vibration [22,26], and the wave speed has a profound effect on the accuracy with which the leak can be located using these devices. Furthemore, the wave attenuation governs the maximum distance from the leak that each of the sensors can be positioned for the correlator to work effectively [23-26].

In models that are used to study leak noise propagation, it is necessary to input soil parameters, such as bulk soil density, loss factor, and bulk and shear moduli. It is relatively straightforward to estimate the soil bulk density, and a reasonable estimate can be made for the loss factor. 
However, the "stiffness" properties of the soil as seen by the pipe, i.e., the bulk and shear moduli of the soils surrounding the pipe are much more difficult to estimate accurately, and in some cases, these properties have a profound effect on the speed and attenuation of the leak noise in a plastic water pipe. It is important, therefore, to have a good estimate of these properties to ensure that the current models can be validated and further developed to study the dynamic behaviour of water pipe systems for the purposes of leak detection and location. These models can also be used in the development of bench-top virtual pipe test systems, for example [27], which can be used to test and compare the performance of leak noise correlators in a variety of field conditions.

The aim of this paper is to present a method to estimate the storage bulk and shear moduli of soil which surrounds a plastic water pipe, using experimental acoustic or vibration data measured in or on the pipe. A cost function is used to compare experimental data with that from a model, and the soil properties used in the model are adjusted to minimise the difference between the model output and experimental data. The model used in this paper is the one proposed by Gao et al. [24,25], which is a development of previous models [18,23], and is considered to be comprehensive enough to capture all the essential physics, but to be simple enough to be used in a program such as Matlab. The quantity chosen as the output from the model, which forms the basis of the cost function, is the wavenumber of the predominantly fluid-borne wave in the pipe, as this can be calculated from measured data. It is also related to the wave speed and the attenuation, which are the important properties with respect to leak detection.

It is thought that this paper will be of interest to the applied geophysics comunity, as it shows the potential importance of the soil properties on leak noise detection in buried plastic water 
pipes using vibration/acoustics. Further, it presents a practical way to identify these parameters based on measurements made at on the pipe. It is acknowledged that the soil properties will vary depending upon location and depth. In the identification method presented, the soil properties determined are those that directly affect leak noise propagation in the pipe.

The paper is organized as follows. Section 2 describes the analytical model of the buried plastic water-filled pipe system, and discusses the way in which the soil properties affect the predominantly fluid-borne wave in the pipe. The method in which the soil parameters are estimated is presented in Section 3. This is then applied to two sites with different soil properties in Section 4. One of the sites is in the UK where the soil surrounding the pipe has properties that are representative of sandy soil, and one in Brazil, where the surrounding soil has properties that are representative of clay soil. The experimental results are discussed in Section 5, and the paer is then closed with some conclusions in the Section 6 .

\section{Effects of soil properties on the propagation of leak noise}

Fig. 1 shows a typical leak detection problem in a buried plastic water pipe, in which there is a leak at an unknown position. The leak generates broadband noise, which propagates along the pipe to the measurement positions either side of the leak. The out-of-bracket excitation shown in the Fig. 1, which is used to determine the soil properties, is discussed in Sections 3 and 4. Measured leak noise generally has low frequency content, below the pipe ring frequency [18]. In this case the frequency response function (FRF) between the acoustic pressure at the leak location and the measurement position a distance $u$ from the leak is given by [22]

$$
H(\omega, u)=e^{-j k u}
$$


where $k$ is the complex wavenumber of the predominantly fluid-borne wave that is responsible for the propagation of leak noise, and $j=\sqrt{-1}$. The speed, $c$, at which the leak noise propagates in the pipe and the wave amplitude change per unit distance are respectively given by [18]

$$
c=\frac{\omega}{\operatorname{Re}\{k\}} \quad \text { and } \quad A=e^{\operatorname{Im}\{k\}}
$$

The difference in the arrival times of the leak noise at the sensors (time delay) is used to determine the position of the leak from sensor 2, which is given by [22],

$$
d_{2}=\frac{d-c T_{0}}{2},
$$

where $d$ is the distance between the sensors, and $T_{0}=\left(d_{1}-d_{2}\right) / c$ is the time delay estimate, which can be estimated from the peak in the cross-correlation function between the two measured signals $x_{1}(t)$ and $x_{2}(t)$.

It can be seen from Eqs. (2a) and (3) that the real part of the wavenumber, which is inversely proportional to the wave speed, affects the estimate of the leak location. The attenuation of the wave in the pipe, which is given in Eq. (2b) is normally written in terms of $\mathrm{dB} / \mathrm{m}$ as $A(\mathrm{~dB} / \mathrm{m})=-20 \operatorname{Im}\{k\} / \ln (10)$. It is related to the imaginary part of the wavenumber and affects how far the leak noise propagates, and hence how close the sensors need to be to the leak position for a leak noise correlator to work. 
The effects of the soil properties on wave propagation in a buried pipe, such as that shown in Fig. 2, have been investigated by Muggleton et al. [18], Muggleton and Yan [23], Gao et al. [24,25] and Brennan et al. [26]. Here, the most complete model of the buried water pipe system, which is described in [24], is used in the determination of the soil properties. However, it is written in the form shown in [26] which is different to that shown in [24] to clarify the way in which the soil affects the wavenumber and hence the wave speed and its attenuation. Note that the effects of the ground surface are not included in the model as they have been found to have a negligible effect on wave propagation in the pipe above about $100 \mathrm{~Hz}$. This is because the wave that is radiated from the pipe and then reflects from the surface, is very small when it returns to the pipe. The reason for this, is the geometrical spreading of the wave front and the damping in the soil. The wavenumber can be written in terms of the free-field wavenumber of water $k_{\text {water }}$ and the dynamic stiffnesses of the water, the pipe and the soil as

$$
k=k_{\text {water }}\left(1+\frac{K_{\text {water }}}{K_{\text {pipe }}+K_{\text {soil }}}\right)^{\frac{1}{2}} \text {, }
$$

where $k_{\text {water }}=\omega\left(\rho_{\text {water }} / B_{\text {water }}\right)^{\frac{1}{2}}$, which is a function of density $\rho_{\text {water }}$, bulk modulus $B_{\text {water }}$ and angular frequency $\omega$. The term $K_{\text {water }}=2 B_{\text {water }} / a$ is the stiffness of the water and $K_{\text {pipe }}=K_{\text {pipe }}^{(\text {stiff })} /\left(1-v_{\text {pipe }}^{2}\right)+K_{\text {pipe }}^{\text {(inertia) }}$, where $K_{\text {pipe }}^{(\text {stiff })}=E_{\text {pipe }}^{*} h / a^{2}$ is the complex stiffness of the pipewall, and $K_{\text {pipe }}^{\text {(inertia) }}=-\omega^{2} \rho_{\text {pipe }} h$ corresponds to the inertial component, in which $a$ is the mean radius and $h$ is the thickness of the pipe; $\rho_{\text {pipe }}, E_{\text {pipe }}^{*}=E_{\text {pipe }}\left(1+j \eta_{\text {pipe }}\right)$ and $v_{\text {pipe }}$ are the density, complex Young's modulus and Poisson's ratio of the pipe, respectively, and $\eta_{\text {pipe }}$ is the loss 
factor of the pipe. The term $K_{\text {soil }}$ in Eq. (4) denotes the dynamic stiffness of the surrounding soil, as experienced by the pipe. In general, this term is complex with the real part encompassing the stiffness and/or inertial effects of the soil, and the imaginary part representing the damping effects. Both the real and imaginary parts of the soil dynamic stiffness are functions of the shear and bulk moduli of the soil, and it is these properties that are determined from measurements of the wavenumber described in this paper. The expression for the soil dynamic stiffness is a complicated expression given by [24]

$$
K_{\text {soil }}=K_{a}+K_{b}
$$

where

$$
\begin{gathered}
K_{a}=\frac{G_{\text {soil }}^{*}}{a}\left(2+\frac{k_{r}^{R} a k_{r}^{2} a^{2}\left[\frac{H_{0}\left(k_{r}^{R} a\right)}{H_{0}^{\prime}\left(k_{r}^{R} a\right)}\right]\left[\frac{H_{0}\left(k_{d}^{R} a\right)}{H_{0}^{\prime}\left(k_{d}^{R} a\right)}\right]}{k_{r}^{R} a k_{d}^{R} a\left[\frac{H_{0}\left(k_{r}^{R} a\right)}{H_{0}^{\prime}\left(k_{r}^{R} a\right)}\right]+k^{2} a^{2}\left[\frac{H_{0}\left(k_{d}^{R} a\right)}{H_{0}^{\prime}\left(k_{d}^{R} a\right)}\right]}\right) \\
K_{b}=-\frac{K_{\text {pipe }}^{\text {(siff) }}}{\left(1-v_{\text {pipe }}^{2}\right)}\left(\frac{v_{\text {pipe }}^{2}}{\left(1+\frac{S_{1}}{k^{2} a^{2}}\right)}+\frac{j 2 v_{\text {pipe }} S_{2}}{k a\left(1+\frac{S_{1}}{k^{2} a^{2}}\right)}+\frac{S_{2}^{2}}{k^{2} a^{2}\left(1+\frac{S_{1}}{k^{2} a^{2}}\right)}\right)
\end{gathered}
$$

in which

$$
S_{1}=-\frac{G_{\text {soil }}^{*}}{a} \frac{\left(1-v_{p}^{2}\right)}{K_{\text {pipe }}^{\text {(siff) }}}\left(\frac{k_{d}^{R} a k_{r}^{2} a^{2}}{k_{r}^{R} a^{2} k_{d}^{R}\left[\frac{H_{0}\left(k_{r}^{R} a\right)}{H_{0}^{\prime}\left(k_{r}^{R} a\right)}\right]+k^{2} a^{2}\left[\frac{H_{0}\left(k_{d}^{R} a\right)}{H_{0}^{\prime}\left(k_{d}^{R} a\right)}\right]}\right)
$$




$$
S_{2}=\frac{j G_{\text {soil }}^{*}\left(1-v_{p}^{2}\right) k}{K_{\text {pipe }}^{\text {(stiff }}}\left(2-\frac{k_{r}^{2} a^{2}\left[\frac{H_{0}\left(k_{d}^{R} a\right)}{H_{0}^{\prime}\left(k_{d}^{R} a\right)}\right]}{k_{r}^{R} a^{2} k_{d}^{R}\left[\frac{H_{0}\left(k_{r}^{R} a\right)}{H_{0}^{\prime}\left(k_{r}^{R} a\right)}\right]+k^{2} a^{2}\left[\frac{H_{0}\left(k_{d}^{R} a\right)}{H_{0}^{\prime}\left(k_{d}^{R} a\right)}\right]}\right)
$$

The soil radial wavenumbers, $k_{d}^{R}$ and $k_{r}^{R}$, are given by $k_{d}^{R}=\sqrt{k_{d}^{2}-k^{2}}$ and $k_{r}^{R}=\sqrt{k_{r}^{2}-k^{2}}$ where $k_{d}=\omega / c_{d}$ and $k_{s}=\omega / c_{s}$ are the compressional and shear wavenumbers in the surrounding soil, respectively, where $c_{d}=\sqrt{\left(B_{\text {soil }}^{*}+4 G_{\text {soil }}^{*} / 3\right) / \rho_{\text {soil }}}$ and $c_{s}=\sqrt{G_{\text {soil }}^{*} / \rho_{\text {soil }}}$ are the compressional and shear wave speeds in the soil respectively, in which $\rho_{\text {soil }}$ is the bulk density of the soil, $B_{\text {soil }}^{*}=B_{\text {soil }}\left(1+j \eta_{\text {soil }}\right)$ and $G_{\text {soil }}^{*}=G_{\text {soil }}\left(1+j \eta_{\text {soil }}\right)$ are the complex bulk and shear moduli of the soil respectively, in which $B_{\text {soil }}$ and $G_{\text {soil }}$ are storage bulk and shear moduli of the soil respectively, and $\eta_{\text {soil }}$ is the soil loss factor; $H_{0}(\bullet)$ is the Hankel function of zero order and second kind that describes the outgoing waves in the surrounding soil, and ' denotes the spatial derivative.

\section{Algorithm used to identify the soil parameters}

As mentioned in the introduction, the aim of this paper is to determine the storage bulk and shear moduli of the soil surrounding the pipe from measurements of the predominantly fluidborne wave in a buried plastic water pipe. The real and imaginary parts of the pipe wavenumber are extracted from the measured data (which is discussed below). The wave attenuation is calculated from the imaginary part of the wavenumber using Eq. (2b) and the following cost function is formed.

$$
J=J_{1}+J_{2}
$$


in which

$$
J_{1}=\frac{\left\|\operatorname{Re}\left\{k_{m}(\omega)\right\}-\operatorname{Re}\left\{k\left(\hat{B}_{\text {soil }}, \hat{G}_{\text {soil }}, \omega\right)\right\}\right\|}{\left\|\operatorname{Re}\left\{k_{m}(\omega)\right\}\right\|} \quad \text { and } \quad J_{2}=\frac{\left\|A_{m}(\omega)-A\left(\hat{B}_{\text {soil }}, \hat{G}_{\text {soil }}, \omega\right)\right\|}{\left\|A_{m}(\omega)\right\|}
$$

where \|\| denotes the Euclidean norm and $\operatorname{Re}\left\{k_{m}(\omega)\right\}=-\phi(\omega) / d$ is the real part of the measured wavenumber, in which $\phi(\omega)$ is the unwrapped phase of the estimated frequency response function, $T(j \omega)$, between two measured signals $x_{1}(t)$ and $x_{2}(t)$ when a wave is excited in the pipe by an out-of-bracket source as shown in Fig.1. The experimental imaginary part of the wavenumber is given by $\operatorname{Im}\left\{k_{m}(\omega)\right\}=\ln \left(A_{m}\right)$ in which $A_{m}=|T(j \omega)| / d$. The pipe material and geometry are assumed to be known, and the bulk density $\rho_{\text {soil }}$ and loss factor for the soil $\eta_{\text {soil }}$ are assumed to be $2000 \mathrm{~kg} / \mathrm{m}^{3}$ and 0.15 respectively [26]. Note that the bulk densities used in the model are estimates from the literature. They were not measured in the test sites as this would have involved disturbing the soil around the pipes. This, in turn, could have affected the way in which the soil influences the wave propagation in the pipe. As the aim was to determine the soil properties that influence leak noise propagation, and it was known that the stiffness properties of the soil compared to the bulk density have a much greater influence on wave propagation in the pipe, the estimates of the bulk density of the considered to be acceptable for the purposes of this paper.

The two remaining unknowns in the model are therefore estimates of the storage bulk and shear moduli of the soil, given by $\hat{B}_{\text {soil }}$ and $\hat{G}_{\text {soil }}$ respectively. The cost function is minimized using the algorithm shown in Fig. 3. The pattern search algorithm, first introduced by Hooke and 
Jeeves [28], was used as it has better convergence properties than many gradient based conventional search methods. Initial guesses for the bulk and shear moduli are needed, and the algorithm converges quickly, which is when the derivative of the cost function $J^{\prime} \approx 0$.

The first step in the procedure to determine the soil properties is the acquisition and preprocessing of the vibration signals $x_{1}(t)$ and $x_{2}(t)$ measured by the sensors attached at the access points, as showed in Fig. 1. This procedure is described in Section 4. The second step involves the calculation of the wavenumber $k_{m}(\omega)$ from the measured data. This involves estimating the frequency response function (FRF) $T(j \omega)$ from the measured data [26]. The real part of the wave number is calculated from the unwrapped phase $\phi(\omega)$ of the FRF, i.e., $\operatorname{Re}\left\{k_{m}(\omega)\right\}=-\phi(\omega) / d$ and the imaginary part of the wavenumber is given by $\operatorname{Im}\left\{k_{m}(\omega)\right\}=\ln (|T(j \omega)| / d)$. Once these quantities have been calculated, the optimization procedure to identify the optimal values of $\hat{B}_{\text {soil }}$ and $\hat{G}_{\text {soil }}$ is carried out in step 3. It starts with initial estimates for the parameters and it stops when the difference between the predicted and measured wavenumbers is acceptable as depicted in the flowchart in Fig. 3. In the fourth step, the estimated bulk and shear moduli are used in the model for the prediction of wave speed and attenuation, and these are compared with measurements.

\section{Application of the method}

Measurements of two experimental pipe systems, one in the UK and the other one in Brazil, were made and the soil properties were determined using the approach proposed in Section

3. The estimated soil properties are then compared with those found in the literature to check that the method gives reasonable results. The properties of the UK and Brazilian pipe systems, which have very different pipe geometry are given in Tab.1. The UK pipe was 
buried in soil whose properties are representative of sandy soil, and one in Brazil, where the surrounding soil has properties that are representative of clay soil. Estimates of the properties of these soils are given in Tab. 2 extracted from [29-32]. Note that a range of values for the storage bulk and shear moduli are given, and the soil properties of the test sites are expected to fall within these ranges.

Schematic diagrams, together with photographs of both test rigs, are shown in Fig. 4. The UK system consists of a 34 metre long test rig and the static pressure is due to the $1.5 \mathrm{~m}$ head of water in the termination tanks. In this case, the predominantly fluid-borne wave was excited by an underwater loudspeaker using a stepped sine signal increasing frequency from $30 \mathrm{~Hz}$ to 1 $\mathrm{kHz}$ at increments of $1 \mathrm{~Hz}$, and the dynamic pressure was measured using two hydrophones 2 metres apart. More details about these measurements are given in [18]. The Brazilian pipe system is smaller than the UK system and was pressurised with a centrifugal pump (3.4 bar). The predominantly fluid-borne wave in this experimental test rig was excited by opening a valve to simulate a leak, and the measurements were made using accelerometers attached to two access points 7 metres apart. More details about these measurements are given in [26].

To gain some insight into the way in which bulk and shear moduli affect the wave speed and the wave attenuation, the two parts of the cost function given in Eq. (5) are plotted. The first, $J_{1}$ is plotted in Figs. 5a(i) and b(i) for the UK and Brazilian pipe systems, respectively. It shows how the normalized difference between the measured and the modeled real part of the wavenumber behaves over a range of values for the bulk and shear moduli. The second, $J_{2}$ is plotted in Fig, 5 a(ii) and b(ii), for the UK and Brazilian pipe systems, respectively. It shows how the normalized difference between measured and modeled attenuation behaves over a range of values for the bulk and shear moduli. The values of corresponding 
upper and lower bounds were chosen based on the soil where each pipe is buried, as discussed above. Also shown on each of the figures is the local minimum of the surface.

Examining Figs, 5a(i) and b(i), it can be seen that the bulk modulus has a marginal effect on the real part of the wavenumber for both the UK and Brazilian systems. The shear modulus, however, has a profound effect and it appears that there is an optimum value that minimizes the difference between the measured and model real part of the wavenumber. This observation confirms the theoretical work and simulations presented in $[23,24,25,26]$. With the attenuation, however, both bulk and shear moduli have an effect, as can be seen in Fig, 5a(ii) and b(ii), but the effects are different in the UK and Brazilian systems. Thus, the sum of the cost functions of $J_{1}$ and $J_{2}$ contain measurements and parameters that are potentially sensitive to changes in the storage bulk and shear modulus of the soil and so can be used, through an optimization procedure, to estimate these properties. To solve the optimization problem in Eq. (6), the initial estimates of the soil bulk and shear moduli point were chosen in each case, as the average of the upper and lower bounds.

Table 3 shows the estimated values for soil parameters identified by the optimization algorithm. Comparing these values with the range of values given in Tab. 2, it can be seen that the values of the bulk modulus and the shear modulus are within the ranges of those expected. It should be noted that there can be reasonable confidence in the estimated shear modulus in both the UK soil and the Brazilian soil, as they are within the range of parameters expected. However, although there can be a similar degree of confidence in the estimate of the bulk modulus for the UK system, this is not the case for the Brazilian system. The reason for this can be seen by examining Fig, 5b(i) and (ii). It can be seen that for clay, the bulk modulus has very little effect 
on either the wave speed or the wave attenuation, which are the measured quantities. This fact has been discussed in [23] and [26]. As mentioned previously, compared to the bulk modulus, the shear modulus has a much greater effect on the wave speed and hence the real part of the measured wavenumber. Furthermore, the reason why the bulk modulus has very little effect on the wave attenuation in the clay soil, is because the wave speed in the pipe is much smaller than the dilatational wave speed in the soil, due to the large bulk modulus. This means that a dilatational wave does not radiate from the pipe and hence does not propagate energy into the soil causing little wave attenuation in the pipe. More details about this phenomenon are given in [26]. Note from Tab. 2 that the estimated bulk modulus is $4.0 \times 10^{9} \mathrm{~N} / \mathrm{m}^{2}$, which is very high and at the upper limit of the expected range. As the bulk modulus has a negligible effect on the wave speed and the attenuation, there is little confidence on this estimate.

\section{Discussion}

The estimated values are used in the model to calculate the real part of the wavenumber and attenuation, which are shown together with the experimental results for the UK system in Fig. 6 and for the Brazilian system in Fig. 7. Also shown in the figures are shaded areas, which represent the corresponding predicted quantities when either the shear modulus is fixed to the optimum value and the bulk modulus is varied between the values given in Tab. 2 and vice versa. The shaded areas are discussed later. For both the UK and the Brazilian systems, it can be seen that in general terms, there is good agreement between the experimental and the model prediction using the estimated values of the shear and bulk moduli. The noise in the experimental data is evident. The large deviations in the measured attenuation compared to the predictions are also evident at low frequencies. There are a number of possible reasons for this, but perhaps one of the main ones is that the surface of the ground is neglected in the model for simplicity. In the model it is assumed that the soil is homogeneous and of infinite extent. This 
is a poor approximation when the wavelength in the soil is much larger than the depth of the buried pipe. As the wavelength decreases with frequency, the model becomes a better representation of the physical system at higher frequencies. Notwithstanding the errors at low frequencies, it should be noted that the aim in this work is to determine the soil properties, and using a more complex model that includes the ground effect, would not have an appreciable effect on this.

Consider now the shaded area in Fig. 6 (for the UK system). It can be seen in Figs. 6a(i) and b(i), that when the shear modulus is fixed to the optimum value and the bulk modulus is varied, there is very little effect on the real part of the wavenumber, but there is an appreciable effect on the wave attenuation. In Figs. $6 a(i i)$ and $6 b(i i)$, it can be seen that when the bulk modulus is fixed to the optimum value and the shear modulus is varied then the main effect is on the real part of the wavenumber, but there is a small effect on the wave attenuation. Thus, this confirms that the optimisation procedure described in Section 3 should yield good estimates for the bulk and shear moduli, as the shear modulus has a predominant effect on the real part of the wavenumber and the bulk modulus has a predominant effect on the wave attenuation.

Consider now the shaded area in Fig. 7 (for the Brazilian system). Unlike for the UK system in which the soil is sandy, for the Brazilian system with clay soil, the bulk modulus has practically no effect on either the real part of the wavenumber or the wave attenuation, as can be seen in Figs. 7a(i) and 7b(i). However, it can be seen Figs. 7a(ii) and 7b(ii), that when the bulk modulus is fixed to the optimum value and the shear modulus is varied then there is a profound effect on both the real part of the wavenumber, and on the wave attenuation. Thus, the optimisation procedure described in Section 3 will only yield a good estimate for the shear modulus. 
Fig. 8 shows the measured and the predicted wave speeds from the model, calculated using Eq. (2a). Also plotted in the Fig. 8 are shaded areas as in Figs. 6 and 7. It can be seen that for both the UK and Brazilian systems the wave speeds marginally decrease as frequency increases, and this is mainly due to the mass loading effect of the soil as discussed in [26]. The average, however is approximately $375 \mathrm{~m} / \mathrm{s}$ for the UK pipe system and $540 \mathrm{~m} / \mathrm{s}$ for the Brazilian pipe system. The larger shear modulus stiffness of the clay soil in the Brazilian system compared to the sandy soil in the UK system is largely responsible for this difference, as discussed in [26]. The deviations in the experimental data from the predictions are evident at low frequencies. This is due, in part, to the reasons discussed above for the attenuation, but in this case, it is also possible because the wave speed is determined from the real part of the wavenumber, which in turn is determined from the phase of the measured frequency response function. This phase difference is small at low frequencies and is effectively determined by subtracting two relatively large numbers, and so is particularly sensitive to noise in the measurements. Examining the shady areas, it is clear that the shear modulus has a profound effect on the wave speed and the bulk modulus has practically no effect as predicted in [23].

\section{Conclusions}

This paper has presented a methodology for the identification of the storage bulk and shear moduli of soil in which a plastic water pipe is buried. The approach involves excitation of the predominantly fluid-borne wave in the pipe, and sensing this wave at two positions using either hydrophones or accelerometers attached to pipe fittings. The measured data are compared with corresponding predicted data from a model, and the soil properties are then adjusted in the model to minimize the differences between the model and the measurement using an optimization algorithm. To demonstrate the efficacy of the method it was applied to two different sites, one in the UK, where the soil properties surrounding the pipe are representative 
of sandy soil, and one in Brazil, where the surrounding soil has properties that are representative of clay soil. In both types of soil, it was found that the shear modulus has a profound effect on the speed of the predominantly fluid-borne wave in the pipe, whereas the bulk modulus has an effect on the attenuation of this wave in the sandy soil, but not in the clay soil. Thus, it was possible to determine the bulk and the shear moduli for a pipe buried in sandy soil, but it in the clay soil it was only possible to determine the shear modulus. This, however, does not diminish the efficacy of the method, as the objective of the paper was to determine the soil properties that affect the properties of the fluid-borne wave, as this wave is the main carrier of leak noise.

\section{Acknowledgements}

The authors would like to thank the financial support provided by the São Paulo Research Foundation (FAPESP) under Grant numbers 2013/50412-3 and 2017/14432-0.

\section{References}

[1] A.C.D. Royal, P.R. Atkins, M.J. Brennan, D.N. Chapman, H. Chen, A.G. Cohn, K.Y. Foo, K.F. Goddard, R. Hayes, T. Hao, P.L. Lewin, N. Metje, J. M. Muggleton, A. Naji, G. Orlando, S.R. Pennock, M.A. Redfern, A.J. Saul, S.G. Swingler, P. Wang and C.D.F Rogers, Site assessment of multiple-sensor approaches for buried utility detection. International Journal of Geophysics, (2011) Article ID 496123. Doi: https://doi.org/10.1155/2011/496123

[2] J.M. Muggleton, M.J. Brennan and Y. Gao, Determining the location of buried plastic water pipes from measurements of ground surface vibration, Journal of Applied Geophysics, vol. 75 (2011), pp. 54-61. Doi: https://doi.org/10.1016/j.jappgeo.2011.06.030 
[3] J.M. Muggleton and B. Papandreou, A shear wave ground surface vibration technique for the detection of buried pipes, Journal of Applied Geophysics, vol. 106 (2014), pp. 164-162. Doi: https://doi.org/10.1016/j.jappgeo.2014.04.021

[4] G. Bièvre, P. Lacroix, L. Oxarango, D. Goutaland, G. Monnot and Y. Fargier, Integration of geotechnical and geophysical techniques for the characterization of a small earth-filled canal dyke and the localization of water leakage, Journal of Applied Geophysics, vol. 139 (2017), pp. 1-15. Doi: https://doi.org/10.1016/j.jappgeo.2017.02.002

[5] S. J. Ocaña-Levario, E. P. Carreño-Alvarado, D. Ayala-Cabrera and J. Izquierdo, GPR image analysis to locate water leaks from buried pipes by applying variance filters, Journal of Applied Geophysics, vol. 152 (2018), pp. 236-247. Doi: https://doi.org/10.1016/j.jappgeo.2018.03.025

[6] F.C.L. de Almeida, M.J. Brennan, P.F. Joseph, S. Dray, S. Whitfield and A. T. Paschoalini, Measurement of wave attenuation in buried plastic water distribution pipes, Journal of Mechanical Engineering, vol. 60, no. 5 (2014), pp. 298-306. Doi: https://doi.org/10.5545/sv jme.2014.1830

[7] O. Hunaidi and W.T. Chu, Acoustic characteristics of leak signals in water distribution pipes, Applied Acoustics, vol. 58, no. 3 (1999), pp. 235-254. Doi: https://doi.org/10.1016/S0003-682X(99)00013-4

[8] O. Hunaidi, W.T. Chu, A. Wang and W. Guan, Detecting leaks in plastic water distribution pipes, Journal of the American Water Works Association, vol. 92, no. 2 (2000), pp. 82-94. Doi: https://doi.org/10.1002/j.1551-8833.2000.tb08819.x

[9] T.C. Lin and G.W. Morgan, Wave propagation through fluid contained in a cylindrical, elastic shell, Journal of the Acoustical Society of America, vol. 28, no. 6 (1956), pp. 11651176. Doi: ttps://doi.org/10.1121/1.1908583 
[10] J. Greenspon, Vibrations of thick and thin cylindrical shells surrounded by water, Journal of the Acoustical Society of America, vol. 33, no. 10 (1961), pp.1321-1328. Doi: https://doi.org/10.1121/1.1908429

[11] C.R. Fuller and F.J. Fahy, Characteristics of wave-propagation and energy-distributions in cylindrical elastic shells filled with fluid, Journal of Sound and Vibration, vol. 81, no. 4 (1982) 501-518. Doi: https://doi.org/10.1016/0022-460X(82)90293-0

[12] B.K. Sinha, T.J. Plona, S. Kostek, S. K. Chang, Axisymmetric wave propagation in fluid loaded cylindrical shells. I: theory, Journal of the Acoustical Society of America, vol 92, no. 2 (1992), pp. 1132-1143. Doi: https://doi.org/10.1121/1.404040

[13] R.J. Pinnington and A.R. Briscoe, Externally applied sensor for axisymmetrical waves in a fluid-filled pipe, Journal of Sound and Vibration, vol. 173, no. 4 (1994), pp. 503-516. Doi: https://doi.org/10.1006/jsvi.1994.1243

[14] R.J. Pinnington, The axisymmetric wave transmission properties of pressurized flexible tubes. Journal of Sound Vibration, vol. 204, no. 2 (1997), pp. 271-89. Doi: https://doi.org/10.1006/jsvi.1997.0938

[15] Y.A. Khulief, A. Khalifa, R.B. Mansour and M.A. Habib. Acoustic detection of leaks in water pipelines using measurements inside pipe. Journal of Pipeline Systems Engineering, vol. 3, no. 2 (2012), pp. 47-54. Doi: https://doi.org/10.1061/(ASCE)PS.19491204.0000089

[16] W.M. Ewing, W.S. Jardetzky and F. Press, Elastic Waves in Layered Media, McGrawHill, New York, 1957.

[17] T. Akiyoshi and K. Fuchida, Soil-pipeline interaction through a frictional interface during earthquakes, Soil Dynamics Earthquake Engineering, vol. 3, no 1 (1984), pp. 27-34. Doi: https://doi.org/10.1016/0261-7277(84)90024-X 
[18] J.M. Muggleton, M.J. Brennan and P.W. Linford, Axisymmetric wave propagation in fluid-filled pipes: wavenumber measurements in in vacuo and buried pipes, Journal of Sound and Vibration, vol. 270 (2004), pp. 171-190. Doi: https://doi.org/10.1016/S0022460X(03)00489-9

[19] J.X. Liu, T.Y. Li, T.G. Liu and J. Yan, Vibration characteristic analysis of buried pipes using the wave propagation approach, Applied Acoustics, vol. 66, n. 3 (2005), pp. 353-364. Doi: https://doi.org/10.1016/j.apacoust.2004.06.010

[20] H. Jia, M. Jing and L.R. Joseph, Guided wave propagation in single and double layer hollow cylinders embedded in infinite media, Journal of the Acoustical Society of America, vol. 129, no.2 (2011), pp. 691-700. Doi: https://doi.org/10.1121/1.3531807

[21] Y. Nassira, H. Rajaie and R.T. Faal, Three dimensional vibration analysis of a buried pipeline with slip conditions, Soil Dynamics and Earthquake Engineering, vol. 31, no. 12 (2011), pp.1629-1639. Doi: https://doi.org/10.1016/j.soildyn.2011.06.005

[22] Y. Gao, M.J. Brennan, P.F. Joseph, J.M. Muggleton and O. Hunaidi, A model of the correlation function of leak noise in buried plastic pipes. Journal of Sound and Vibration, vol. 277, no. 1-2 (2004), pp. 133-148. Doi: https://doi.org/10.1016/j.jsv.2003.08.045

[23] J.M. Muggleton and J. Yan, Wavenumber prediction and measurement of axisymmetric waves in buried fluid filled pipes: Inclusion of shear coupling at a lubricated pipe/soil interface, Journal of Sound and Vibration, vol. 332, no. 5 (2013), pp. 1216-1230. Doi: https://doi.org/10.1016/j.jsv.2012.10.024

[24] Y. Gao, F. Sui, J.M. Muggleton and J. Yang, Simplified dispersion relationships for fluiddominated axisymmetric wave motion in buried fluid-filled pipes. Journal of Sound and Vibration, vol. 375 (2016), pp. 386-402. Doi: https://doi.org/10.1016/j.jsv.2016.04.012 
[25] Y. Gao, Y. Liu and J.M. Muggleton, Axisymmetric fluid-dominated wave in fluid-filled plastic pipes: Loading effects of surrounding elastic medium. Journal of Applied Acoustics, vol. 116 (2017), pp. 43-49, Doi: https://doi.org/10.1016/j.apacoust.2016.09.016

[26] M.J. Brennan, M. Karimi, J.M. Muggleton, F.C.L de Almeida, F. K. de Lima, P.C. Ayala, D. Obata, A.T. Paschoalini and N. Kessissoglou, On the effects of soil properties on leak noise propagation in plastic water distribution pipes, Journal of Sound and Vibration, vol. 427 (2018), pp. 120-133. Doi: https://doi.org/10.1016/j.jsv.2018.03.027

[27] M.J. Brennan, F.C. de Lima, F.C.L. de Almeida, P.F. Joseph, A.T. Paschoalini, A virtual pipe rig for testing acoustic leak detection correlators: Proof of concept. Applied Acoustics, vol. 102 (2016), pp. 137-145. Doi: http://dx.doi.org/10.1016/j.apacoust.2015.09.015

[28] R. Hooke and T. A. Jeeves, Direct search solution of numerical and statistical problems, J. ACM, vol. 8, no. 2, (1961), pp. 212-229.

Url: https://dl.acm.org/citation.cfm?doid=321062.321069

[29] F. E. Richart Jr, J. R. Hall Jr and R. D. Woods, Vibration of Soil and Foundation, PrenticeHall International, Englewood Cliffs (1970) New Jersey, USA.

[30] A. C. J. Luo, M. Dehghani and H. R. Hamidzadeh, Vibration of Soil and Foundation Literature review, Proceedings of IMECE2005 International Mechanical Engineering Congress and Exposition, November 5-11 (2005) Orlando, Florida, USA.

[31] American Association of State Highway and Transportation Officials (AASHTO), Standard Specifications for Highway Bridges, (1996), 16th edition, Washington, D.C., USA.

[32] Kezdi, A. Handbook of Soil Mechanics (1990), 4th vol, Elsevier, Amsterdam. 


\section{Figures}

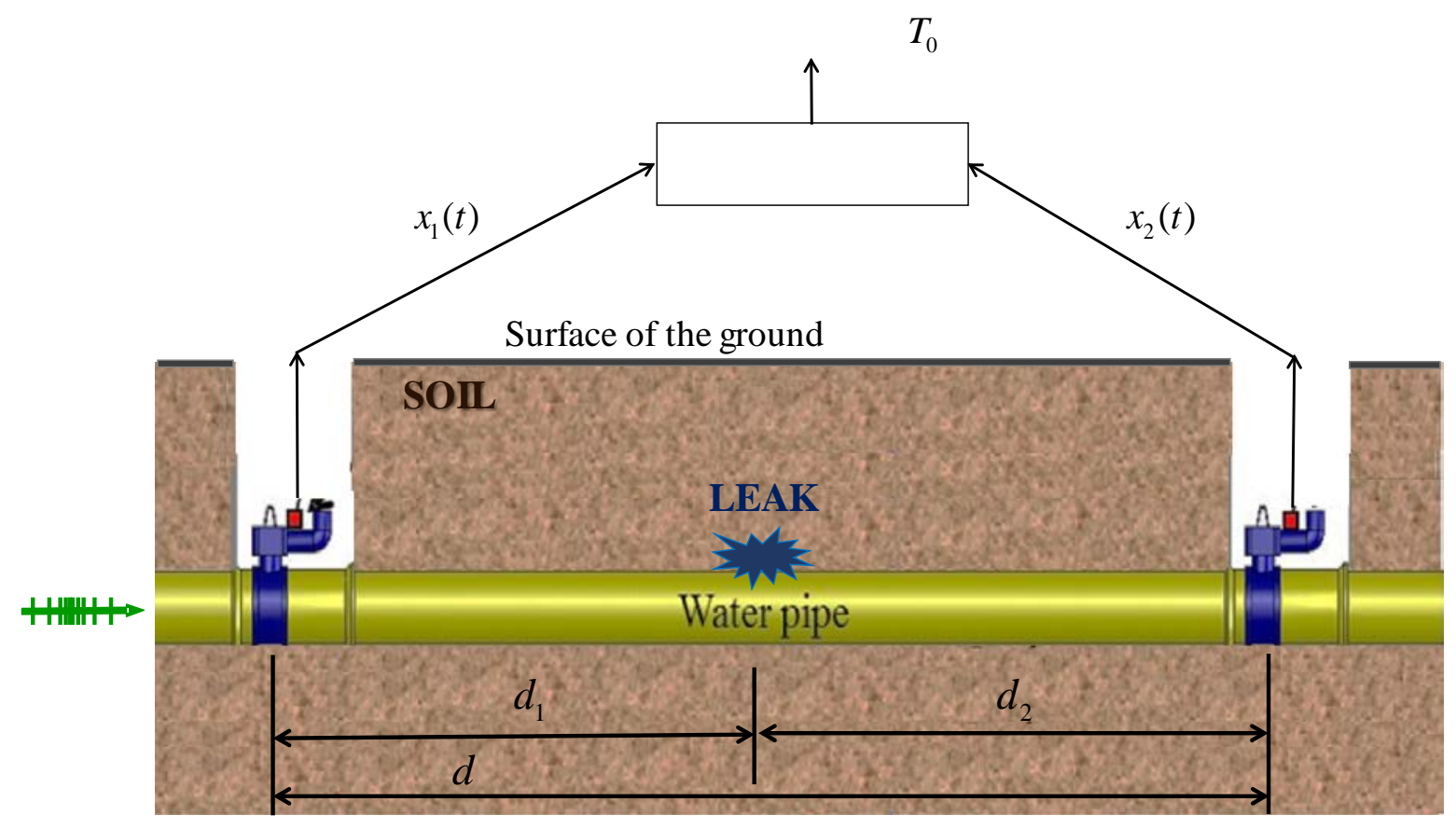

Figure 1. Schematic of the set up for leak detection and soil property estimation in a buried plastic water pipe using vibration measurement. The out-of-bracket excitation is used for soil property estimation. 


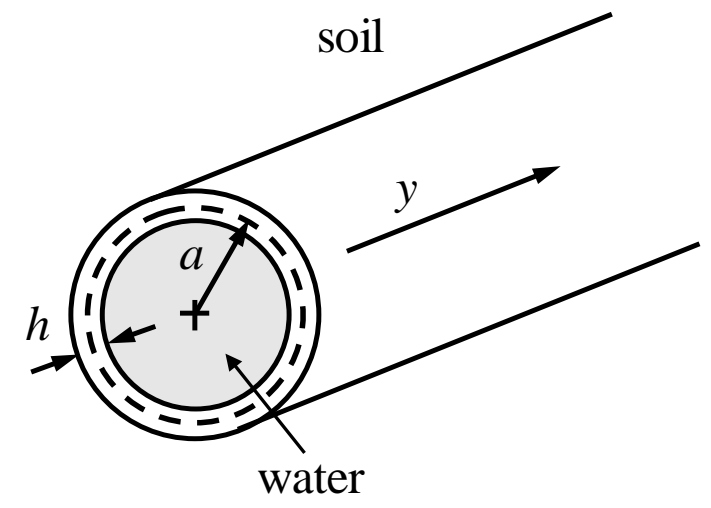

Figure 2. Schematic diagram of the buried pipe showing the pipe geometry. 
STEP 1. Data acquisition and processing

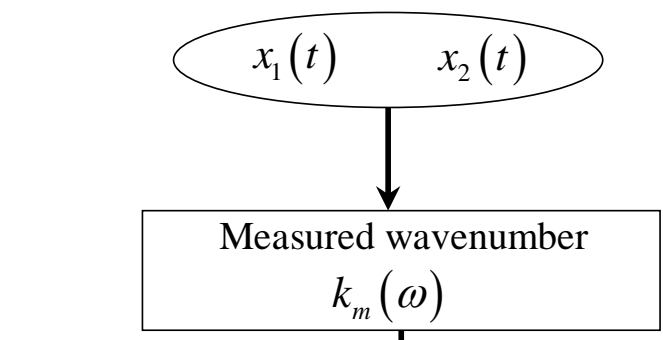

STEP 2. Wavenumber estimation from the cross-spectral density
STEP 3. Estimation of optimal soil parameters

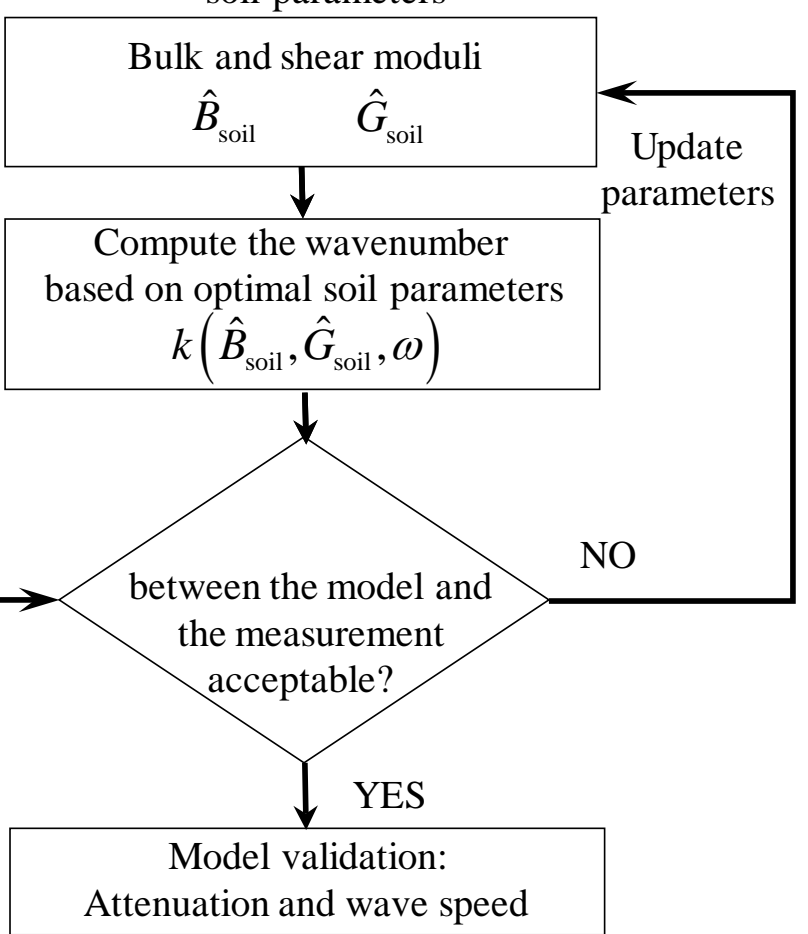

Figure 3. Computational flowchart illustrating the methodology used to identify the soil parameters by using measured vibration data from the buried plastic water pipe system shown in Fig. 1. 
(a)

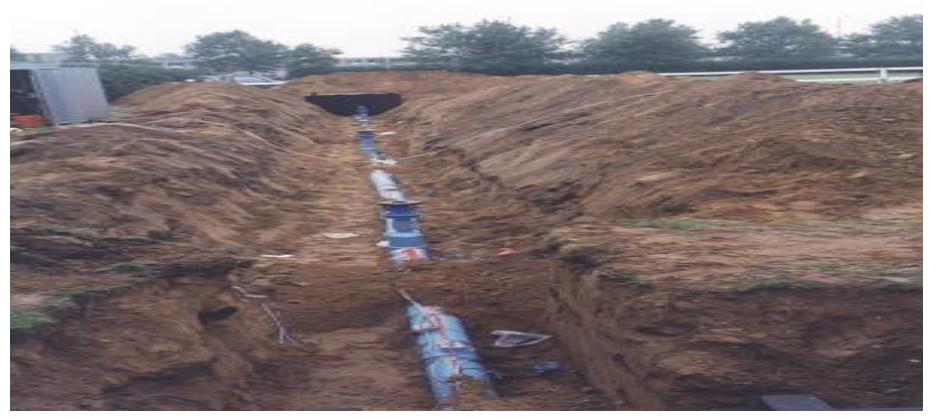

Specially adapted loudspeaker

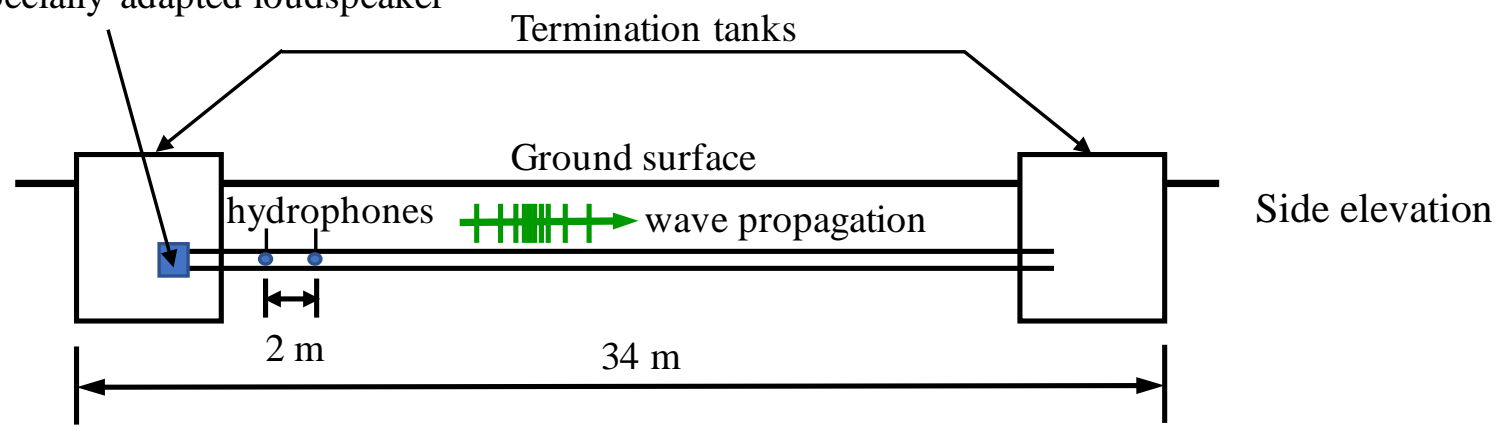

(b)
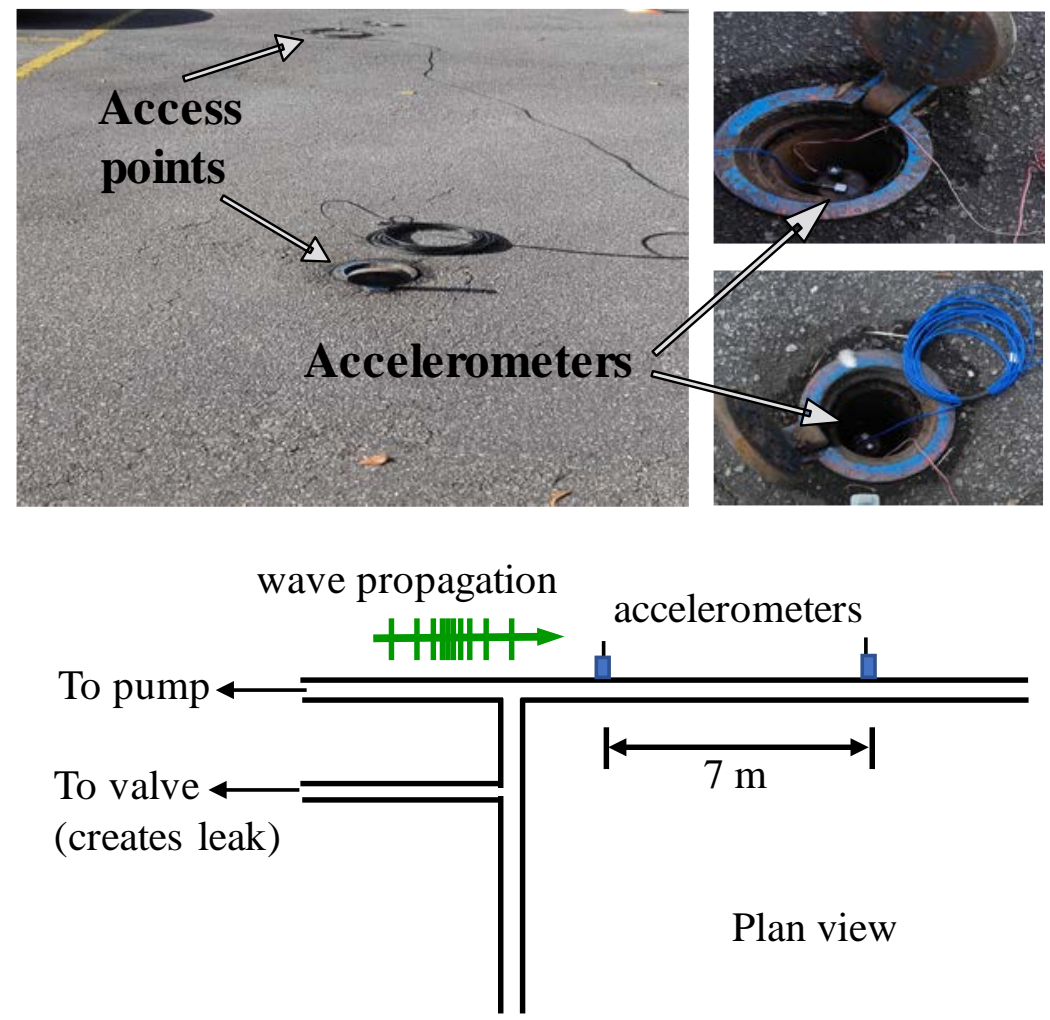

Figure 4. Schematics of the two test-rigs (not to scale). (a) UK test rig with sandy soil, (b) Brazil test rig with clay-like soil. The properties of the pipes are given in Table 1. 


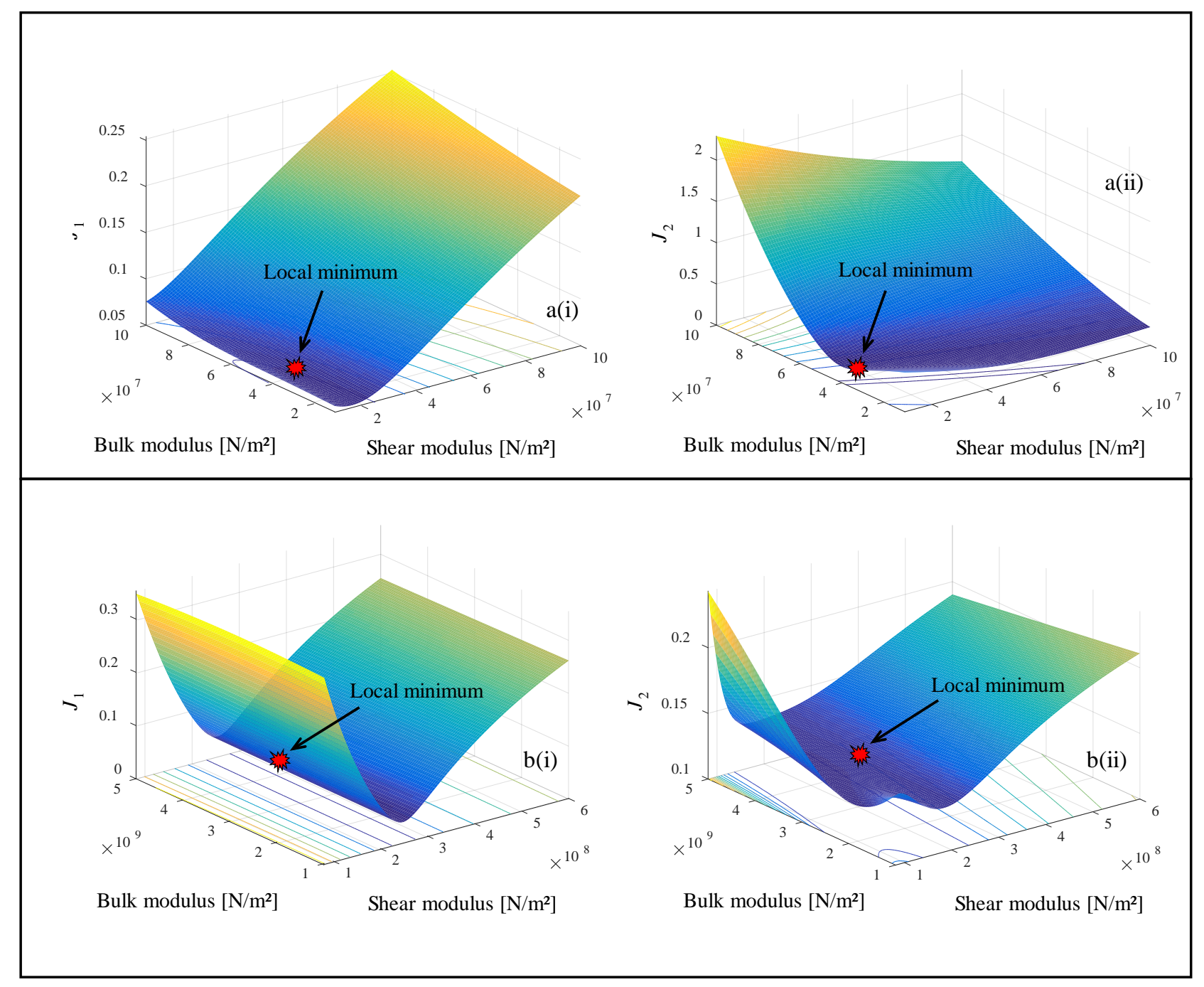

Figure 5. Behaviour of $J_{1}$ and $J_{2}$ as a function the bulk and shear moduli, (a) UK test rig, (b) Brazilian test rig. (i) $J_{1}$ which is related to the real part of the wavenumber, which in turn is related to the wave speed (ii) $J_{2}$ which is related to the attenuation of the wave. 

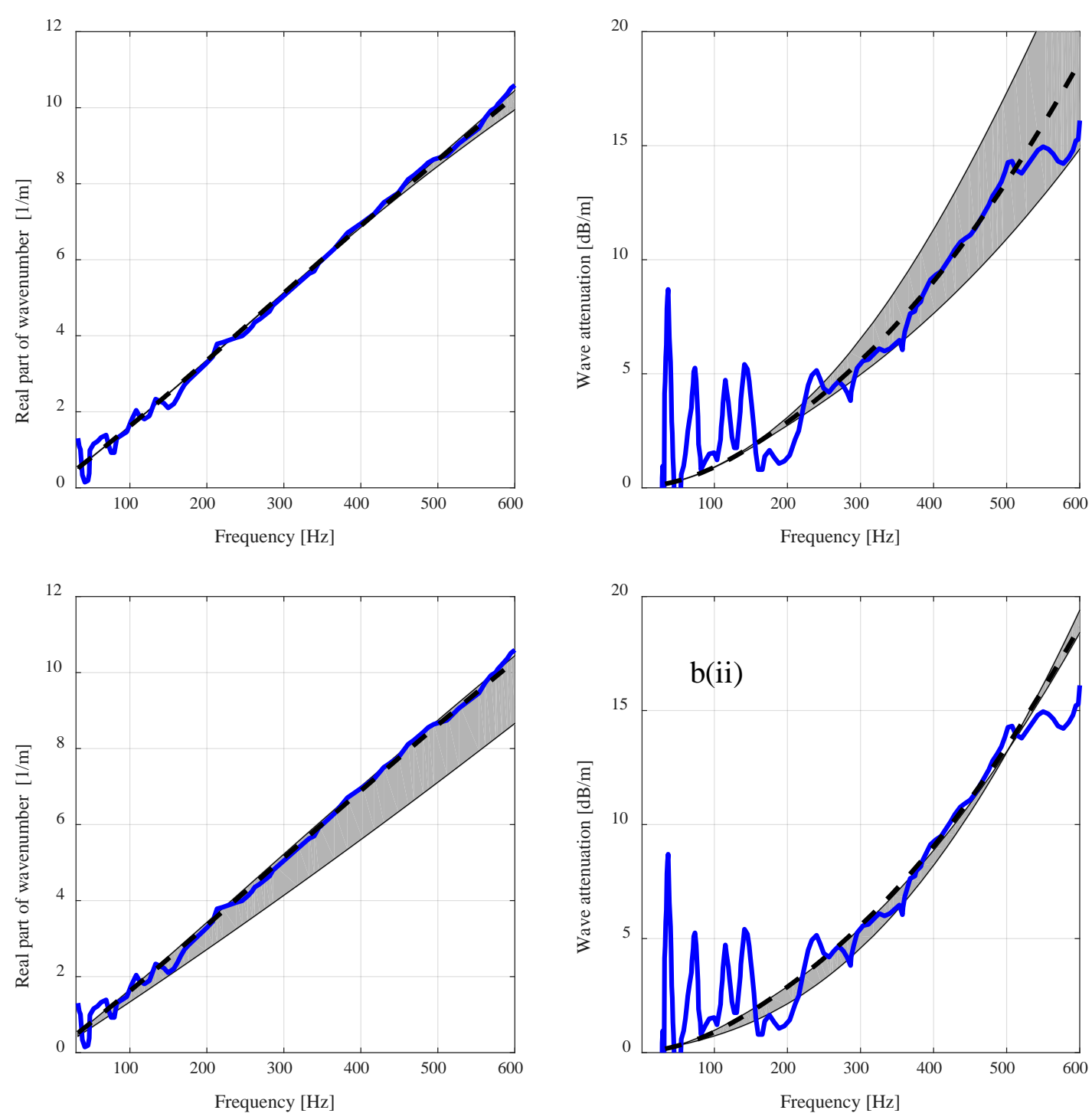

Figure 6. Measured and estimated properties of the predominantly fluid-borne wave for the UK test rig. (a) Wavenumber, (b) Wave attenuation. (i) Shear modulus is set to $1.5 \times 10^{7} \mathrm{~N} / \mathrm{m}^{2}$ and the bulk modulus is varied. (ii) Bulk modulus is set to $4.0 \times 10^{7} \mathrm{~N} / \mathrm{m}^{2}$ and the shear modulus is varied. Solid blue line, experimental; black dashed line, estimated through the optimisation procedure. The grey area shows the estimated quantity over the range of soil parameters given in Tab. 2. 

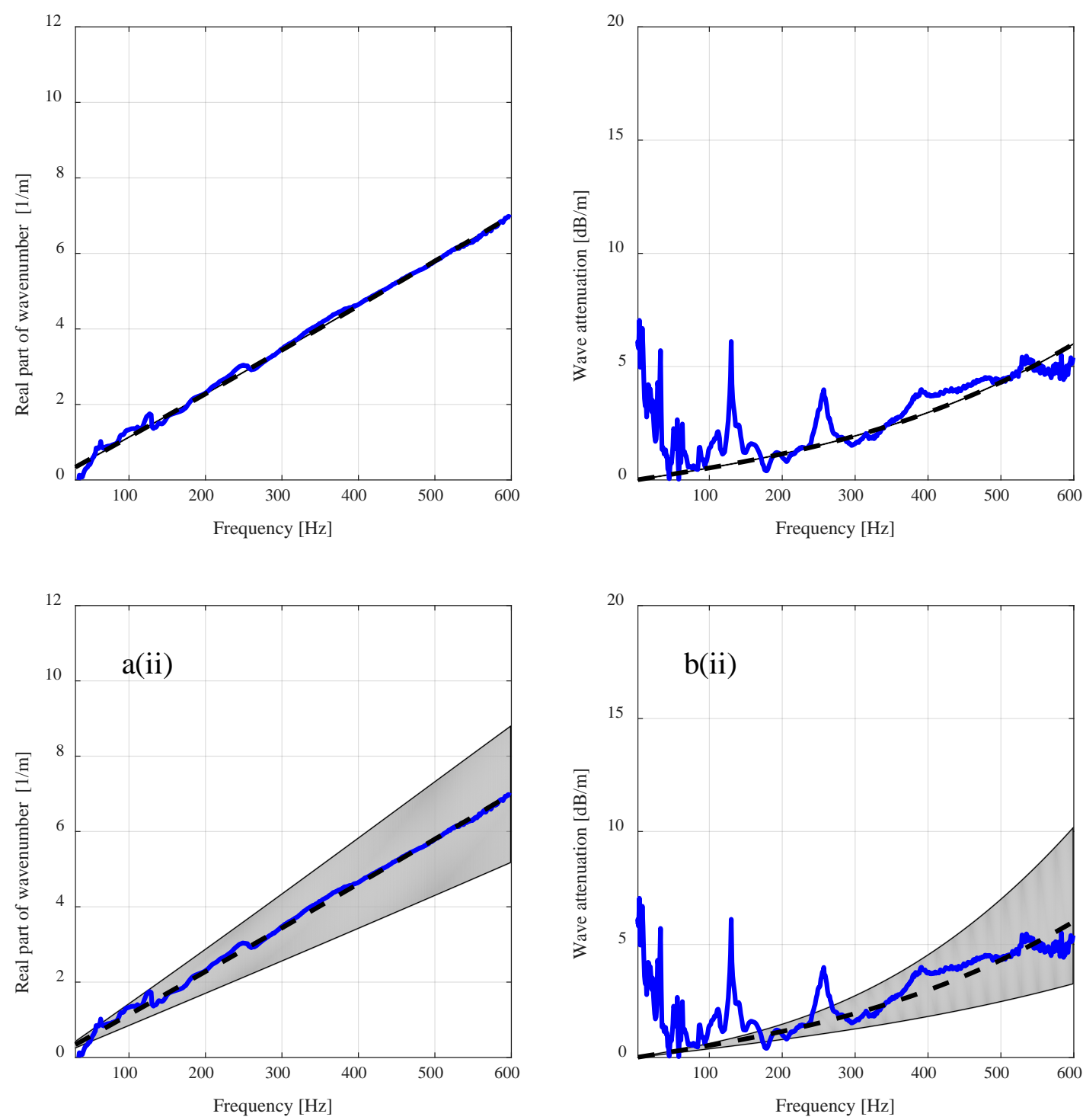

Figure 7. Measured and estimated properties of the predominantly fluid-borne wave for the Brazilian test rig. (a) Wavenumber, (b) Wave attenuation. (i) Shear modulus is set to $2.4 \times 10^{8} \mathrm{~N} / \mathrm{m}^{2}$ and the bulk modulus is varied. (ii) Bulk modulus is set to $4.0 \times 10^{9} \mathrm{~N} / \mathrm{m}^{2}$ and the shear modulus is varied. Solid blue line, experimental; black dashed line, estimated through the optimisation procedure. The grey area shows the estimated quantity over the range of soil parameters given in Tab. 2 . 
UK system
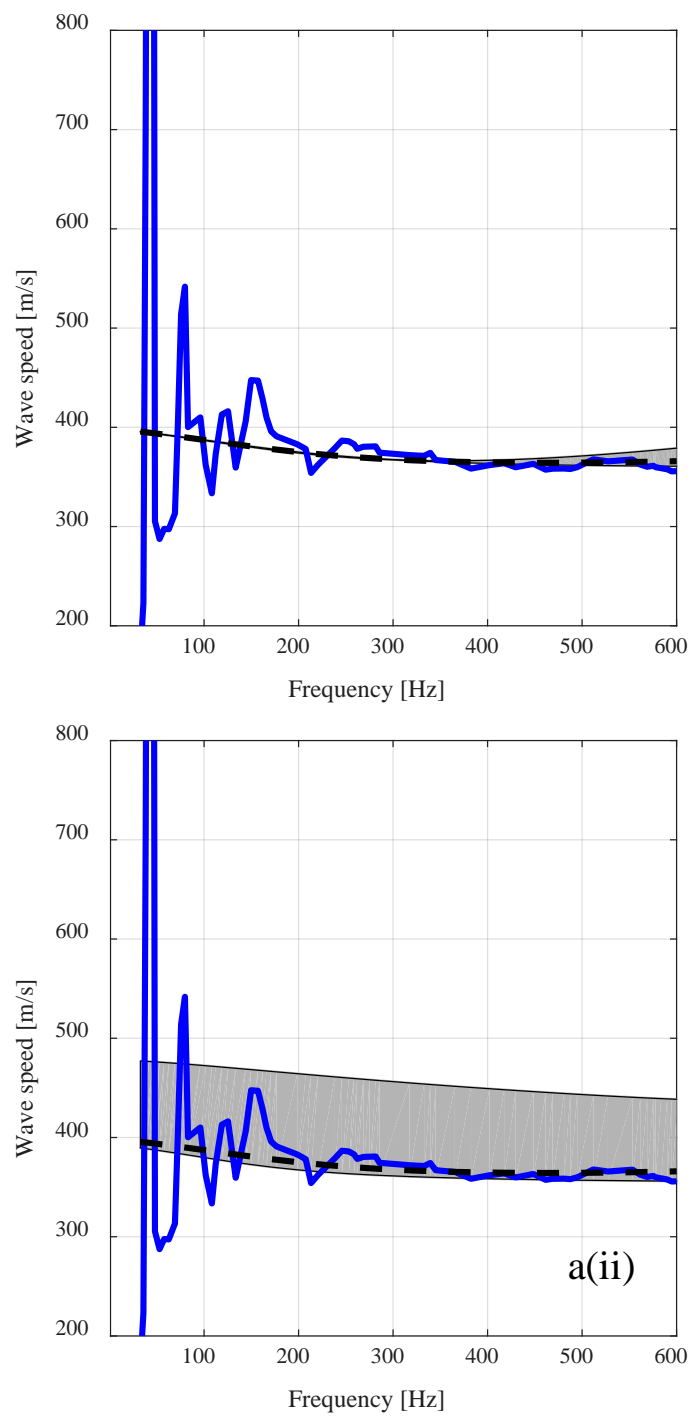

Brazilian system
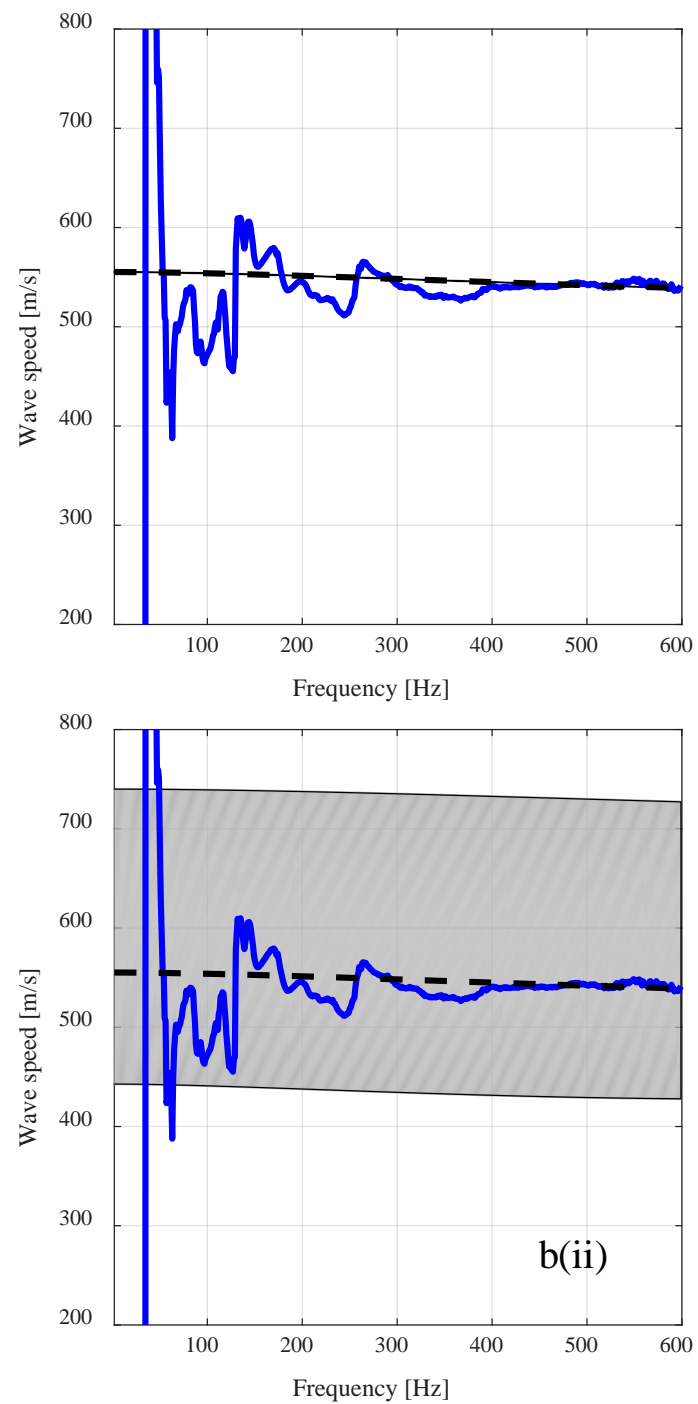

Figure 8. Measured and estimated wave speeds of the predominantly fluid-borne wave for (a) UK test rig., (b) Brazilian test rig. (i) Shear modulus is set to the optimal values and the bulk modulus is varied. (ii) Bulk modulus is set to the optimum values and the shear modulus is varied. Solid blue line, experimental; black dashed line, estimated through the optimisation procedure. The grey area shows the estimated over the range of soil parameters values given in Tab. 2. 


\section{Tables}

Table 1. Pipe Properties of the UK and Brazilian pipe systems.

\begin{tabular}{c|c|c}
\hline Properties & UK & Brazil \\
\hline Young's modulus $E_{\text {pipe }}\left[\mathrm{N} / \mathrm{m}^{2}\right]$ & $2 \times 10^{9}$ & $2 \times 10^{9}$ \\
Density $\rho_{\text {pipe }}\left[\mathrm{kg} / \mathrm{m}^{3}\right]$ & 900 & 900 \\
Loss factor $\eta_{\text {pipe }}$ & 0.06 & 0.06 \\
Mean radius $[\mathrm{mm}]$ & 84.5 & 35.8 \\
Wall thickness $[\mathrm{mm}]$ & 11 & 3.4 \\
\hline
\end{tabular}

Table 2. Soil properties extracted from [29-32].

\begin{tabular}{|c|c|c|}
\hline Properties & UK & Brazil \\
\hline Type of Soil & Sandy & Clay \\
\hline $\begin{array}{l}\text { Range of bulk modulus values } \\
\qquad B_{\text {soil }}\left[\mathrm{N} / \mathrm{m}^{2}\right]\end{array}$ & $2 \times 10^{7}-7 \times 10^{7}$ & $8 \times 10^{8}-4 \times 10^{9}$ \\
\hline $\begin{array}{l}\text { Range of shear modulus } \\
\text { values } G_{\text {soil }}\left[\mathrm{N} / \mathrm{m}^{2}\right]\end{array}$ & $1 \times 10^{7}-4 \times 10^{7}$ & $1 \times 10^{8}-5 \times 10^{8}$ \\
\hline Bulk Density $\rho_{\text {soil }}\left[\mathrm{kg} / \mathrm{m}^{3}\right]$ & 2000 & 2000 \\
\hline Loss factor $\eta_{\text {soil }}$ & 0.15 & 0.15 \\
\hline
\end{tabular}

Table 3. Estimates for the soil parameters identified through pattern search algorithm.

\begin{tabular}{c|c|c}
\hline Optimization parameter & UK pipe system & $\begin{array}{c}\text { Brazilian pipe } \\
\text { system }\end{array}$ \\
\hline Bulk modulus $\hat{B}_{\text {soil }}\left[\mathrm{N} / \mathrm{m}^{2}\right]$ & $4.0 \times 10^{7}$ & $4.0 \times 10^{9}$ \\
Shear modulus $\hat{G}_{\text {soil }}\left[\mathrm{N} / \mathrm{m}^{2}\right]$ & $1.5 \times 10^{7}$ & $2.4 \times 10^{8}$ \\
\hline
\end{tabular}

